Case Report

\title{
A Fatal Case of Isolated Left Side Endocarditis in an Intravenous Drug Abuser
}

\author{
Saurabh Puri', Vikrant Panwar ${ }^{2}$ \\ ${ }^{1}$ DNB Resident, Max Super Specialty Hospital, Vaishali, Ghaziabad, Uttar Pradesh, India. \\ ${ }^{2}$ Former DNB Resident, Max Super Specialty Hospital, Vaishali, Ghaziabad, Uttar Pradesh, India. \\ DOI: https://doi.org/10.24321/2349.7181.202115
}

\section{I $\quad \mathbf{N} \quad \mathbf{F} \quad \mathbf{O}$}

\author{
Corresponding Author: \\ Saurabh Puri, Max Super Specialty Hospital, \\ Vaishali, Ghaziabad, Uttar Pradesh, India. \\ E-mail Id: \\ saurabhpuri119@gmail.com \\ Orcid Id: \\ https://orcid.org/0000-0003-4514-0237 \\ How to cite this article: \\ Puri S, Panwar V. A Fatal Case of Isolated Left \\ Side Endocarditis in an Intravenous Drug Abuser. \\ J Adv Res Med. 2021;8(3):19-21. \\ Date of Submission: 2021-10-03 \\ Date of Acceptance: 2021-12-16
}

\section{$\begin{array}{llllllll}\mathbf{A} & \mathbf{B} & \mathbf{S} & \mathbf{T} & \mathbf{R} & \mathbf{A} & \mathbf{C} & \mathbf{T}\end{array}$}

\begin{abstract}
The incidence of infective endocarditis (IE) in intravenous drug use (IVDU) has risen over the past few decades. Usually, right-sided valves have been thought to get affected. However, we came across a case of isolated left side endocarditis in an intravenous drug user and wanted to report it.
\end{abstract}

Keywords: Left Side Endocarditis, Intravenous Drug Abuser, Methicillin Resistant Staphylococcus Aureus, Aortic Valve Vegetation

\section{Introduction}

Infective endocarditis leads to tissue destruction and formation of vegetation due to microbial infection of the heart valve (native or prosthetic) or the mural endocardium. The incidence of infective endocarditis is more in females compared to males with 1.7-7.2 cases/one lakh-year. The most common causative organism is Staphylococcus aureus and a well-known risk factor is intravenous drug use.

\section{Case Report}

A 32-year-old male, known IV drug abuser (pheniramine maleate), came from another hospital at around 2:24 PM. He was admitted there with complaints of high-grade fever, cough with expectoration from the last 5 days, along with shortness of breath and chest pain from the last 1 day. The patient was received in $E R$ with severe respiratory distress, state of shock (BP - 70 systolic) and altered sensorium. On examination, the findings were as follows: pulse $-133 / \mathrm{min}$, $\mathrm{SpO}_{2}-80 \%$ with 15 litre $\mathrm{O}_{2}, \mathrm{BP}-70$ systolic, respiratory rate
- 34/min with multiple healed needle puncture wounds over bilateral cubital fossa. On systemic examination, B/L extensive crepitations were heard all over the lung field. He was agitated and restless with no localising sign. S1 and S2 were audible with no murmur. He was intubated and put on ventilatory support. Inotropic support was started (NorAd - 15ml/hr), CVP line insertion and Foley's catheterisation were done along with IV fluids, IV steroids, IV antibiotics (injection meropenem and injection teicoplanin), IV antimalarial (inj artesunate) and antiviral (oseltamivir). Complete blood count was done which revealed $\mathrm{Hb}-12.3$ $\mathrm{g} / \mathrm{dl}$, total leucocyte count $-19.49 \times 10^{9} / \mathrm{L}$, with neutrophils $89 \%$ and marked thrombocytopenia $\left(40 \times 10^{\%} / \mathrm{L}\right)$. Renal function test revealed acute kidney injury (serum urea $-61 \mathrm{mg} / \mathrm{dl}$, serum creatinine $-1.9 \mathrm{mg} / \mathrm{dl}$ ). Liver function test revealed raised liver enzymes (SGOT - 65, SGPT - 56). Workup for fever was done and typhidot, peripheral smear for malaria parasite, malaria antigen, dengue NS1, dengue serology were sent which were negative. Viral markers ( $\mathrm{HbsAG}, \mathrm{HIV}$ ) were sent which were negative, but HCV was 
reactive. D-dimer and FDP were sent which were elevated (6674 and $>20$ respectively). 2 D-ECHO was done which revealed mobile echogenic mass seen on aortic valve likely vegetation, mild MR, mild TR, mild AR, no RWMA, EF - 50\%, Grade 1 LVDD, RVSP - 40 mm Hg, No LA/ LV clot/ $P E$ seen. He was admitted to the Internal Medicine and Neurology Department with a provisional diagnosis of severe sepsis with shock and MODS - altered sensorium, acute respiratory distress syndrome, acute kidney injury, and infective endocarditis. Urgent cardiology and pulmonology opinions were asked. The patient was shifted for a CT scan around 6 PM where he had a cardiac arrest post-CT in CT Room. CPR was done according to ACLS protocol, but he could not be revived and was declared dead. Paired blood culture was sent which revealed the growth of methicillinresistant Staphylococcus aureus (MRSA). The final diagnosis was infective endocarditis-aortic valve vegetation (Blood C/S- MRSA +ve, known IV drug abuser) with ? cardiogenic pulmonary oedema with septic shock and MODS (AKI, respiratory failure, altered sensorium, DIC) with $\mathrm{HCV}+\mathrm{ve}$ status.

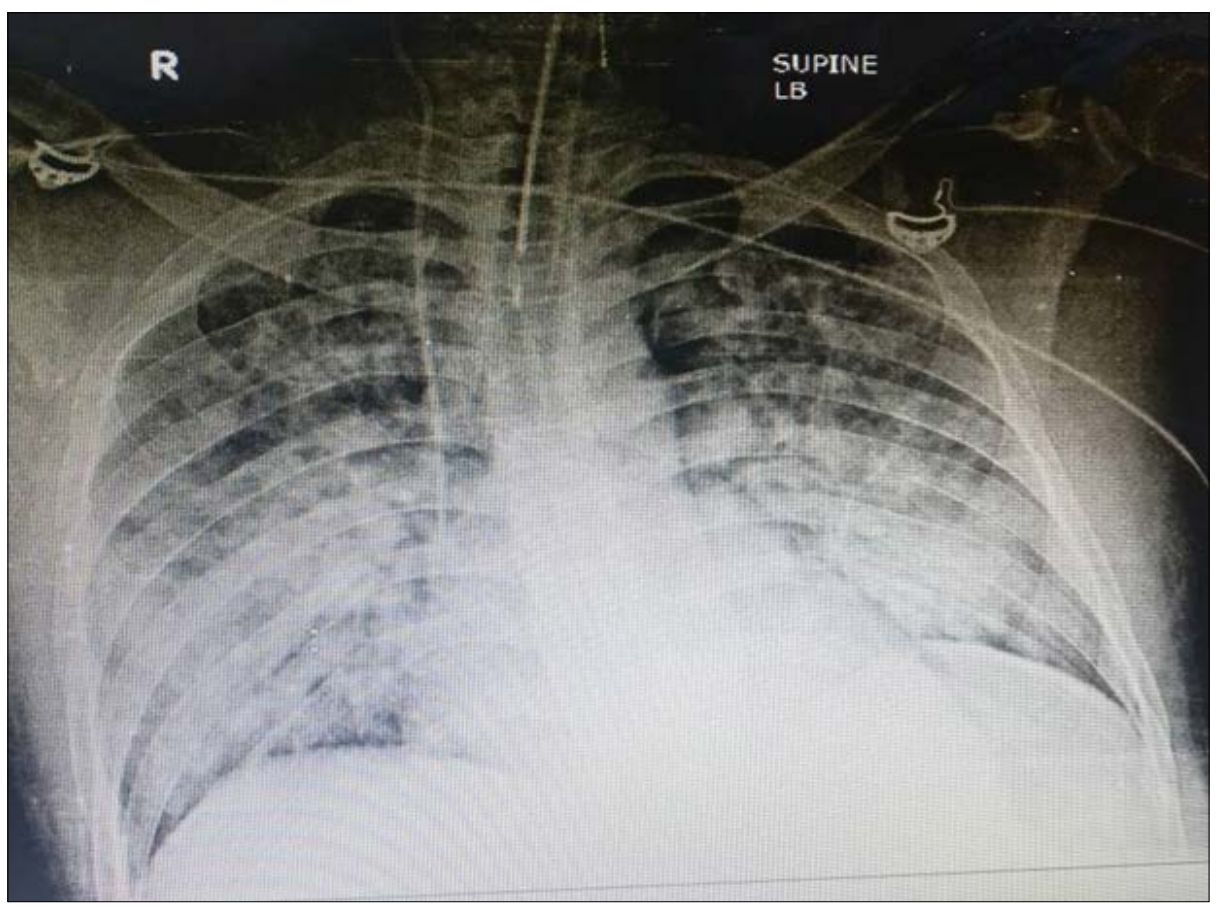

Figure I.Chest X Ray PA view: Diffuse heterogenous opacities involving both lungs

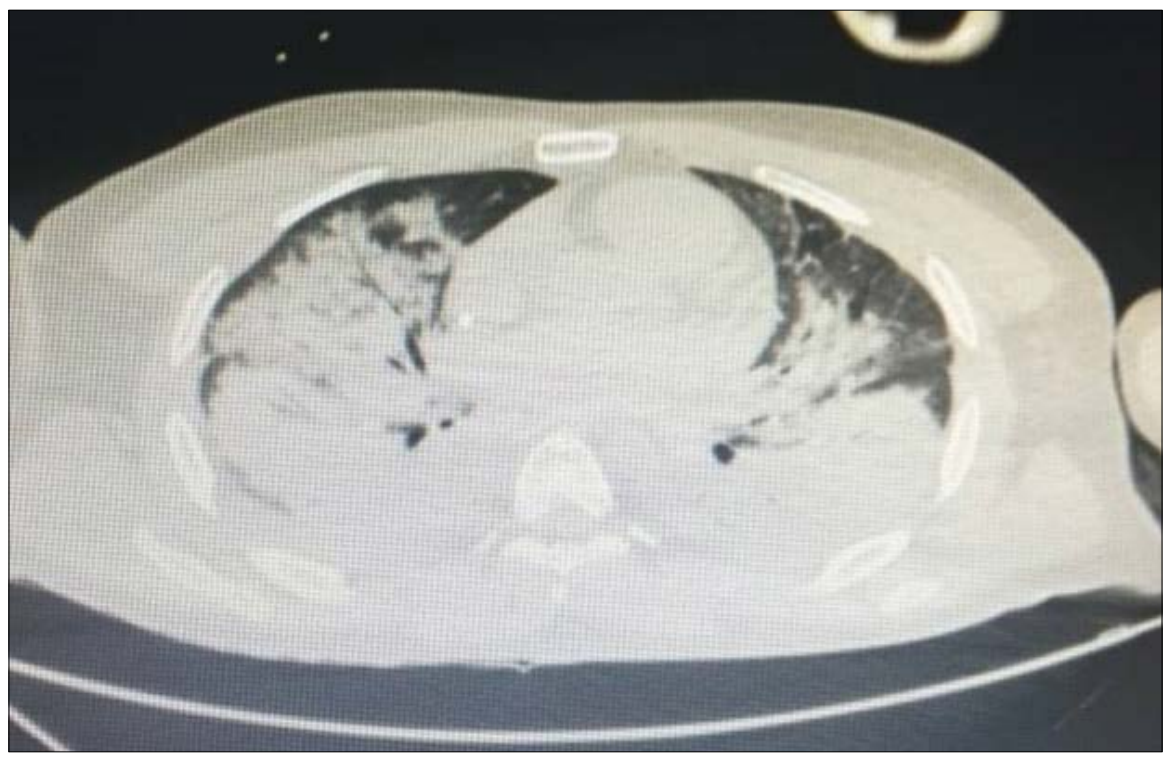

Figure 2.HRCT Chest: Diffuse heterogenous opacities involving both lung suggestive of consolidation/pulmonary edema 


\section{Discussion}

Infective endocarditis (IE) was recognised to be a complication of injection drug use (IDU) in the 1950s. ${ }^{1}$ In one study, as compared to other causes, IDU associated IE was found to be more prevalent in the younger population and females. ${ }^{2}$ The most common cause of infective endocarditis among intravenous drug users is Staphylococcus aureus, which accounts for more than half of the cases. ${ }^{3}$ Communityassociated methicillin-resistant Staphylococcus aureus (MRSA) was also first observed in intravenous drug abusers. Streptococci, enterococci, gram-negative bacilli were the other organisms involved. ${ }^{4}$ In the general population as a whole, right-sided endocarditis is less common than leftsided endocarditis. Most cases of right-sided IE occur among IDUs, and many case series note that most IDUs with IE have right-sided infection. ${ }^{5}$ However, in one series of 67 IDUs, left-sided IE was more common than right-sided IE (57\% versus $40 \%$ ). The left-sided involvement is associated with a worse prognosis than the right-sided involvement. ${ }^{6}$

\section{Conclusion}

Isolated left side endocarditis is a rare entity in intravenous drug abuser making it difficult to diagnose leading to significant mortality. The purpose of this case report is to make physicians aware about community acquired MRSA and initiating broad spectrum antibiotic coverage with gram positive coverage.

\section{Conflict of Interest: None}

\section{References}

1. Hussey $\mathrm{HH}$, Katz S. Infections resulting from narcotic addiction; report of 102 cases. Am J Med 1950;9:186. [PubMed] [Google Scholar]

2. Schranz AJ, Fleischauer A, Chu VH, Wu LT, Rosen DL. Trends in drug use-associated infective endocarditis and heart valve surgery, 2007 to 2017: a study of statewide discharge data. Ann Intern Med. 2019;170(1):31-40. [PubMed] [Google Scholar]

3. Mathew J, Addai T, Anand A, Morrobel A, Maheshwari $P$, Freels S. Clinical features, site of involvement, bacteriologic findings, and outcome of infective endocarditis in intravenous drug users. Arch Intern Med. 1995;155:1641. [PubMed] [Google Scholar]

4. Levine DP, Crane LR, Zervos MJ. Bacteremia in narcotic addicts at the Detroit Medical Center. II. Infectious endocarditis: a prospective comparative study. Rev Infect Dis. 1986;8:374. [PubMed] [Google Scholar]

5. Ortiz-Bautista C, López J, García-Granja PE, Sevilla T, Vilacosta I, Sarria C, Olmos C, Ferrera C, Saez C, Gomez I, Roman JA. Current profile of infective endocarditis in intravenous drug users: the prognostic relevance of the valves involved. Int J Cardiol. 2015;187:472. [PubMed] [Google Scholar]
6. Graves MK, Soto L. Left-sided endocarditis in parenteral drug abusers: recent experience at a large community hospital. South Med J. 1992;85:378. [PubMed] [Google Scholar] 